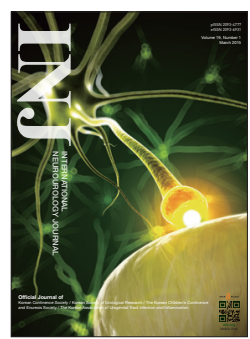

\title{
Population-Based Survey on Disease Insight, Quality of Life, and Health-Seeking Behavior Associated With Female Urinary Incontinence
}

\author{
Hoon $\mathrm{Choi}^{1}$, Jae Young Park ${ }^{1}$, Jeong Kyun $\mathrm{Yeo}^{2}$, Mi Mi Oh${ }^{1}$, Du Geon Moon ${ }^{1}$, Jeong Gu Lee ${ }^{1}$ Jae Hyun Bae \\ ${ }^{1}$ Department of Urology, Korea University College of Medicine, Seoul, Korea \\ ${ }^{2}$ Department of Urology, Inje University Seoul Paik Hospital, Inje University College of Medicine, Seoul, Korea
}

Purpose: To evaluate disease insight, personal distress, and healthcare-seeking behavior of women with urinary incontinence (UI) to improve women's health in Korea.

Methods: In October 2012, 500 Korean women residing around Seoul, Incheon, and Gyeonggi-do were selected by random sampling for a population-based cross-sectional survey conducted by computer-aided telephone interview. Sixteen questions, which included information on demographic characteristics, information sources, disease insights, and general health-seeking behavior, were used for data collection.

Results: Among the responders, 23.8\% experienced UI, the prevalence of which increased with increasing age; $83.3 \%$ knew about UI through the mass media out of $98.2 \%$ apprehended people. Regarding general awareness of UI, $77.2 \%$ understood that UI is caused by aging. A total of $48.7 \%$ of subjects experienced societal restrictions because of UI. Most women in their 30s (25.6\%) acquired UI information from the Internet, while those in their 50s and 60s (50-59 years, 51.1\%; 60-64 years, 42.4\%) learned about UI through friends. Among subjects who did not have UI, $89.37 \%$ intended to see a doctor or consult a professional if they developed UI (83.2\%). Among those with UI, however, only 59.0\% had talked about UI; $79.7 \%$ had talked with friends or associates, whereas only $23.2 \%$ had consulted a professional.

Conclusions: Most respondents tended to obtain information on UI through the mass media. Subjects who did not have UI expressed their intention to consult a professional if they developed UI, while the percentage of subjects with UI who had consulted a professional was very low. Many women are ashamed of UI in Korea, which may be changed by providing efficient advertising with the right information and establishing a new perception of UI.

Keywords: Urinary Incontinence; Prevalence; Health Care

- Grant \& Fund Support: This study was supported by a National Research Foundation of Korea (NRF) grant funded by the Korea Government (MSIP) (No. 2011-0020128). This study was based on a survey of the Korean Continence Society campaign supported by Yuhan-Kimberly (Seoul, Korea).

- Conflict of Interest: No potential conflict of interest relevant to this article was reported.

\section{INTRODUCTION}

Urinary incontinence (UI) is defined by the International Con- tinence Society as "the complaint of any involuntary leakage of urine" [1]. A recent review reported that $25 \%$ to $45 \%$ of women have UI worldwide [2,3]. Although UI is not a life-threatening

Corresponding author: Jae Hyun Bae (DD http://orcid.org/0000-0001-9862-3545 Department of Urology, Korea University Ansan Hospital, Korea University College of Medicine, 123 Jeokgeum-ro, Danwon-gu, Ansan 425-707, Korea E-mail: doc71377@hanmail.net / Tel: +82-31-412-5190 / Fax: +82-31-412-5194 Submitted: March 9, 2015 / Accepted after revision: March 23, 2015 
condition, it does have a physical and psychological effect on women's daily lives. Many women believe that UI is a normal consequence of childbirth and aging, and therefore deny treatment. Today, there are various effective treatments for UI; however, many women tend to manage their UI silently rather than by asking for professional help. Embarrassment and shamefulness are the primary reasons for concealing this problem [4].

Increased knowledge of the comorbidities and personal burden specifically associated with UI may improve the management of this condition. However, there has been little effort to create public awareness of this problem, despite recent commercial advertising on the internet and other media for the many types of products currently available.

The prevalence of UI increases with advancing age. Additionally, a rapidly growing aged population is also associated with a concomitant social burden [5]. In order to promote women's public health and to organize healthcare services related to UI, the issues on disease insight and health-seeking behavior of UI patients need to be addressed.

Therefore, using data from the Korean Continence Society campaign program, we conducted the present study in order to investigate disease insight, personal distress, and healthcareseeking behavior associated with UI in adult women to promote women's well-being in Korea.

\section{MATERIALS AND METHODS}

In October 2012, 500 Korean women were selected by random sampling for a population-based cross-sectional survey. Data were collected from the capital area of Korea (Seoul, Incheon, and Gyeonggi-do) by computer-aided telephone interview for 20 days. The interviewer asked each respondent to participate in a survey and dropped when responders refuse to answer.

The questionnaires used data collected from Korean Continence Society Committee. Questionnaires were divided into sections on demographic characteristics, information sources, disease insights, and health-seeking behaviors. The length of time necessary to answer the questions varied; however, 30 minutes was generally sufficient. Selected participants' questionnaires were as follows:

1. Have you ever heard of UI?

2. Have you received any kind of information about UI within the past 3 months?

3. From whom the information of UI was received within past 3 months?
4. Have you experienced UI in the past 6 months?

5. Have you ever discussed or been willing to discuss UI with others?

6. Have you ever discussed or are you willing to discuss UI with friends, family, doctors, or etc.?

7. Why did you not discuss your UI problem?

8. Do you agree that UI is a natural outcome of aging or childbirth?

9. Do you agree that normal activities, including mild exercise, are restricted by UI?

10. Do you agree that social activities are restricted by UI?

11. Do you agree that UI can be handled by the use of protective products?

12. Do you agree that UI can be overcome by exercise or diet control?

13. Do you feel discomfort by UI?

14. Has your participation in activities decreased?

15. Have you every neglected to treat your UI because of shame?

16. Have you ever hesitated to buy protective products for UI?

Statistical analyses and results of the socio-demographic and clinical characteristics of the variables were performed using SPSS ver. 16 (SPSS Inc., Chicago, IL, USA). Analysis of variance was used to assess differences between groups, and correlation analysis was performed using the chi-square test.

\section{RESULTS}

Among the 500 subjects, 140 (28.0\%) were aged 30 to 39 years, 140 (28.0\%) were aged 40 to 49 years, 140 (28.0\%) were aged $50-59$ years, and $80(16.0 \%)$ were aged more than 60 years. The area distribution of the subjects was as follows: 181 (36.2\%) from Seoul, 172 (34.4\%) from Gyeonggi-do, and 147 (29.4\%) from Incheon.

With respect to childbirth, 343 subjects (68.6\%) reported having a normal delivery history, while 157 subjects (31.4\%) did not. Regarding employment, 295 subjects (59.0\%) were fulltime homemakers, and 205 subjects (41.0\%) reported having a full-time or part-time job. Regarding education level, 256 subjects (51.2\%) reported a below high school level education, 236 subjects (47.2\%) reported receiving education above the high school level, and 8 subjects (1.6\%) did not provide a response to this question.

As a response to question 1 (Have you ever heard of UI?), 491 subjects (98.2\%) among the 500 had heard of UI. Respon- 
dents aged more than 60 years and those with higher educational levels showed greater awareness of UI (Table 1).

The 491 subjects who had heard of UI were asked question 2 (Have you received any kind of information about UI within the past 3 months?), the number of people who received information about UI within the past 3 months increased with age. In addition, subjects aged more than 60 years were more aware of UI than those aged less than 60 years. The 117 subjects who experienced UI were more aware of UI than the 374 UI-naive subjects, and normal delivery history did influence the differ- ences in this information (Table 2).

For question 3 (From whom the information of UI was received within past 3 months?), 162 subjects (33\% of the 491 subjects who had heard of UI) received most of their information from the television/radio (83.3\%). Subjects older than 50 years received more information from friends (50-59 years, $51.1 \%$; 60-64 years, $42.2 \%$ ), and subjects in their 30s received more information from the Internet (25.6\%).

Additionally, subjects who experienced UI received more information from friends (51.1\%) than UI-naive subjects (27.0\%)

Table 1. Data on question 1

\begin{tabular}{|c|c|c|c|c|c|c|c|c|c|}
\hline \multirow[b]{2}{*}{ Question 1} & \multicolumn{5}{|c|}{ Age (yr) } & \multicolumn{2}{|c|}{ Education level } & \multicolumn{2}{|c|}{ Normal delivery } \\
\hline & $\begin{array}{c}\text { Total } \\
(n=500)\end{array}$ & $\begin{array}{c}30-39 \\
(n=140)\end{array}$ & $\begin{array}{c}40-49 \\
(n=140)\end{array}$ & $\begin{array}{c}50-59 \\
(n=140)\end{array}$ & $\begin{array}{c}60-64 \\
(n=80)\end{array}$ & $\begin{array}{l}\text { Under high } \\
\text { school } \\
(\mathrm{n}=256)\end{array}$ & $\begin{array}{c}\text { Over high } \\
\text { school } \\
(\mathrm{n}=244)\end{array}$ & $\begin{array}{l}\text { Experienced } \\
\quad(n=343)\end{array}$ & $\begin{array}{c}\text { Naive } \\
(\mathrm{n}=157)\end{array}$ \\
\hline \multicolumn{10}{|c|}{ Have you ever heard of urinary incontinence? } \\
\hline Yes & 98.2 & 98.6 & 100 & 97.9 & 95 & 96.9 & 99.6 & 98.0 & 98.7 \\
\hline No & 1.8 & 1.4 & 0 & 2.1 & 5 & 3.1 & 0.4 & 2.0 & 1.3 \\
\hline
\end{tabular}

Values are presented as percentage.

Table 2. Data on question 2

\begin{tabular}{|c|c|c|c|c|c|c|c|c|c|}
\hline \multirow[b]{2}{*}{ Question 2} & \multicolumn{5}{|c|}{ Age (yr) } & \multicolumn{2}{|c|}{ Urinary incontinence } & \multicolumn{2}{|c|}{ Normal delivery } \\
\hline & $\begin{array}{c}\text { Total } \\
(\mathrm{n}=491)\end{array}$ & $\begin{array}{c}30-39 \\
(n=138)\end{array}$ & $\begin{array}{c}40-49 \\
(n=140)\end{array}$ & $\begin{array}{c}50-59 \\
(n=137)\end{array}$ & $\begin{array}{c}60-64 \\
(n=76)\end{array}$ & $\begin{array}{l}\text { Experienced } \\
\quad(n=117)\end{array}$ & $\begin{array}{c}\text { Naive } \\
(\mathrm{n}=374)\end{array}$ & $\begin{array}{c}\text { Experienced } \\
\quad(\mathrm{n}=336)\end{array}$ & $\begin{array}{c}\text { Naive } \\
(\mathrm{n}=155)\end{array}$ \\
\hline \multicolumn{10}{|c|}{ Have you received any kind of information about urinary incontinence within the past 3 months? } \\
\hline Yes & 33.0 & 28.3 & 30.7 & 34.3 & 43.4 & 40.2 & 30.7 & 33.6 & 31.6 \\
\hline No & 67.0 & 71.7 & 69.3 & 65.7 & 56.6 & 59.8 & 69.3 & 66.4 & 68.4 \\
\hline
\end{tabular}

Values are presented as percentage.

Table 3. Data on question $3^{\text {a) }}$

\begin{tabular}{|c|c|c|c|c|c|c|c|c|c|}
\hline \multirow[b]{2}{*}{ Source } & \multicolumn{5}{|c|}{ Age (yr) } & \multicolumn{2}{|c|}{ Urinary incontinence } & \multicolumn{2}{|c|}{ Normal delivery } \\
\hline & $\begin{array}{c}\text { Total } \\
(\mathrm{n}=162)\end{array}$ & $\begin{array}{c}30-39 \\
(\mathrm{n}=39)\end{array}$ & $\begin{array}{c}40-49 \\
(n=43)\end{array}$ & $\begin{array}{c}50-59 \\
(\mathrm{n}=47)\end{array}$ & $\begin{array}{c}60-64 \\
(n=33)\end{array}$ & $\begin{array}{l}\text { Experienced } \\
\quad(\mathrm{n}=47)\end{array}$ & $\begin{array}{c}\text { Naive } \\
(\mathrm{n}=115)\end{array}$ & $\begin{array}{l}\text { Experienced } \\
(\mathrm{n}=113)\end{array}$ & $\begin{array}{l}\text { Naive } \\
(\mathrm{n}=49)\end{array}$ \\
\hline TV/radio & 83.3 & 84.6 & 93.0 & 83.0 & 69.7 & 78.7 & 85.2 & 80.5 & 89.8 \\
\hline Friends & 34.0 & 17.9 & 23.3 & 51.1 & 42.4 & 51.1 & 27.0 & 38.1 & 24.5 \\
\hline Magazine & 16.0 & 20.5 & 16.3 & 12.8 & 15.2 & 10.6 & 18.3 & 17.7 & 12.2 \\
\hline Internet & 14.8 & 25.6 & 14.0 & 17.0 & - & 17.0 & 13.9 & 11.5 & 22.4 \\
\hline Family & 11.7 & 10.3 & 9.3 & 10.6 & 18.2 & 10.6 & 12.2 & 12.4 & 10.2 \\
\hline Hospital & 6.2 & 5.1 & 4.7 & 12.8 & - & 6.4 & 6.1 & 5.3 & 8.2 \\
\hline Etc. & 2.5 & 2.6 & - & 2.1 & 6.1 & - & 3.5 & 2.7 & 2.0 \\
\hline
\end{tabular}

Values are presented as percentage.

a) From whom the information of UI was received within past 3 months? 
Table 4. Data on question 4

\begin{tabular}{|c|c|c|c|c|c|c|c|}
\hline \multirow[b]{2}{*}{ Question 4} & \multicolumn{5}{|c|}{ Age (yr) } & \multicolumn{2}{|c|}{ Normal delivery } \\
\hline & $\begin{array}{c}\text { Total } \\
(\mathrm{n}=491)\end{array}$ & $\begin{array}{c}30-39 \\
(\mathrm{n}=138)\end{array}$ & $\begin{array}{c}40-49 \\
(n=140)\end{array}$ & $\begin{array}{c}50-59 \\
(n=137)\end{array}$ & $\begin{array}{c}60-64 \\
(n=76)\end{array}$ & $\begin{array}{l}\text { Experienced } \\
(\mathrm{n}=336)\end{array}$ & $\begin{array}{c}\text { Naive } \\
(\mathrm{n}=155)\end{array}$ \\
\hline \multicolumn{8}{|c|}{ Have you experienced urinary incontinence in the past 6 months? } \\
\hline Yes & 23.8 & 13.0 & 23.6 & 32.1 & 28.9 & 29.8 & 11.0 \\
\hline No & 76.2 & 87.0 & 76.4 & 67.9 & 71.1 & 70.2 & 89.0 \\
\hline
\end{tabular}

Values are presented as percentage.

Table 5. Data on questions 8 to 12

\begin{tabular}{|c|c|c|c|c|c|c|c|c|c|}
\hline \multirow[b]{2}{*}{ Questions 8 to 12} & \multicolumn{5}{|c|}{ Age (yr) } & \multicolumn{2}{|c|}{ Urinary incontinence } & \multicolumn{2}{|c|}{ Normal delivery } \\
\hline & $\begin{array}{c}\text { Total } \\
(\mathrm{n}=491)\end{array}$ & $\begin{array}{c}30-39 \\
(n=138)\end{array}$ & $\begin{array}{c}40-49 \\
(n=140)\end{array}$ & $\begin{array}{c}50-59 \\
(n=137)\end{array}$ & $\begin{array}{c}60-64 \\
(n=76)\end{array}$ & $\begin{array}{l}\text { Experienced } \\
\quad(n=117)\end{array}$ & $\begin{array}{c}\text { Naive } \\
(\mathrm{n}=374)\end{array}$ & $\begin{array}{c}\text { Experienced } \\
(n=336)\end{array}$ & $\begin{array}{c}\text { Naive } \\
(\mathrm{n}=155)\end{array}$ \\
\hline \multicolumn{10}{|c|}{ 8. UI is a natural outcome of aging or childbirth } \\
\hline Agree & 77.2 & 79.7 & 81.4 & 73.0 & 72.4 & 88.9 & 73.5 & 78.0 & 75.5 \\
\hline Disagree & 13.4 & 12.3 & 13.6 & 12.4 & 17.1 & 8.5 & 15.0 & 11.6 & 17.4 \\
\hline \multicolumn{10}{|c|}{ 9. Normal activity including mild exercise is restricted by UI } \\
\hline Agree & 77.0 & 77.5 & 77.9 & 74.5 & 78.9 & 70.9 & 78.9 & 75.6 & 80.0 \\
\hline Disagree & 16.7 & 18.1 & 20.0 & 13.9 & 13.2 & 23.1 & 14.7 & 17.9 & 14.2 \\
\hline \multicolumn{10}{|c|}{ 10. Social activity is restricted by UI } \\
\hline Agree & 48.7 & 35.5 & 42.9 & 57.7 & 67.1 & 50.4 & 48.1 & 48.8 & 48.4 \\
\hline Disagree & 42.8 & 58.7 & 50.0 & 29.9 & 23.7 & 41.9 & 43.0 & 42.6 & 43.2 \\
\hline \multicolumn{10}{|c|}{ 11. UI could be handled by the use of protective products } \\
\hline Agree & 60.3 & 74.6 & 67.1 & 48.9 & 42.1 & 62.4 & 59.6 & 58.0 & 65.2 \\
\hline Disagree & 24.2 & 18.1 & 20.7 & 33.6 & 25.0 & 28.2 & 23.0 & 24.1 & 24.5 \\
\hline \multicolumn{10}{|c|}{ 12. UI could be overcome by the use of exercise or diet control } \\
\hline Agree & 58.9 & 68.8 & 59.3 & 54.7 & 47.4 & 59.0 & 58.8 & 59.8 & 56.8 \\
\hline Disagree & 16.1 & 14.5 & 16.4 & 16.8 & 17.1 & 19.7 & 15.0 & 15.2 & 18.1 \\
\hline
\end{tabular}

Values are presented as percentage.

All the responses were expressed as "agree" or "disagree".

UI, urinary incontinence.

(Table 3).

For question 4 (Have you experienced UI in the past 6 months?), the overall incidence of UI was $23.8 \%$. The prevalence rates increased from $13.0 \%$ in the 30 - to 39 -year age group to $28.9 \%$ in over 60 -year age group. Subjects with a normal delivery history were more affected by UI $(29.8 \%)$ than those without a normal delivery history or who had not ever delivered a child (11.0\%) (Table 4).

In response to questions 5 (Have you ever discussed or been willing to discuss UI with others?), among 117 subjects who had experienced UI, 69 subjects (59.0\%) had consulted with others about their UI. Meanwhile, 334 of the 374 UI-naive subjects (89.3\%) were willing to discuss UI with others.

For questions 6 (Have you ever discussed or been willing to discuss UI with others?), 55 subjects (79.7\%) who experienced UI had discussed their UI problem with friends. In addition, 25 subjects (36.2\%) had discussed the issue with family, and only 16 subjects (23.2\%) had discussed the issue with their doctors.

Conversely, 279 UI-naive subjects (83.2\%) were willing to discuss the issue with doctors, 126 subjects (37.7\%) were willing to discuss with friends, and 113 subjects (30.2\%) were willing to discuss with family. 
Table 6. Data on questions 13 to 16

\begin{tabular}{|c|c|c|c|c|c|c|c|}
\hline \multirow[b]{2}{*}{ Questions 13 to 16} & \multicolumn{5}{|c|}{ Age (yr) } & \multicolumn{2}{|c|}{ Normal delivery } \\
\hline & $\begin{array}{c}\text { Total } \\
(\mathrm{n}=117)\end{array}$ & $\begin{array}{c}30-39 \\
(n=18)\end{array}$ & $\begin{array}{c}40-49 \\
(n=33)\end{array}$ & $\begin{array}{c}50-59 \\
(n=44)\end{array}$ & $\begin{array}{c}60-64 \\
(n=22)\end{array}$ & $\begin{array}{l}\text { Experienced } \\
\quad(n=100)\end{array}$ & $\begin{array}{l}\text { Naive } \\
(\mathrm{n}=17)\end{array}$ \\
\hline \multicolumn{8}{|c|}{ 13. Do you feel discomfort because of UI? } \\
\hline Yes & 50.4 & 50.0 & 42.4 & 52.3 & 59.1 & 47.0 & 70.6 \\
\hline No & 47.0 & 50.0 & 57.6 & 43.2 & 36.4 & 50.0 & 29.4 \\
\hline \multicolumn{8}{|c|}{ 14. Has your participation in activities decreased? } \\
\hline Yes & 20.5 & 21.1 & 12.1 & 25.0 & 31.8 & 18.0 & 35.3 \\
\hline No & 76.9 & 88.9 & 84.8 & 72.7 & 63.6 & 80.0 & 58.8 \\
\hline \multicolumn{8}{|c|}{ 15. Have you ever neglected your UI because of shame? } \\
\hline Yes & 25.6 & 22.2 & 18.2 & 29.5 & 31.8 & 26.0 & 23.5 \\
\hline No & 72.6 & 77.8 & 78.8 & 70.5 & 63.6 & 72.0 & 76.5 \\
\hline \multicolumn{8}{|c|}{ 16. Have you ever hesitated to buy protective products for UI? } \\
\hline Yes & 12.0 & 21.1 & - & 11.4 & 31.8 & 12.0 & 11.8 \\
\hline No & 54.7 & 72.2 & 75.8 & 36.4 & 45.5 & 54.0 & 58.8 \\
\hline
\end{tabular}

Values are presented as percentage.

UI, urinary incontinence.

For question 7 (Why did you not discuss your UI problem?), 48 of the 117 subjects (41\%) who experienced UI had never discussed their UI problem because they regarded UI as a minor problem. Furthermore, $64.6 \%$ were ashamed of their UI, and $33.3 \%$ worried about the negative image associated with UI.

Meanwhile, $10.7 \%$ of the 374 UI-naive subjects were not willing to discuss UI. Moreover, $62.5 \%$ felt ashamed of their UI, $22.5 \%$ regarded it as a minor problem, and $7.5 \%$ worried about the negative image.

For questions $8-12$, responses were expressed as a agree or disagree (Table 5). More than $70 \%$ of subjects agreed that UI is a natural outcome of aging or childbirth (question 8) and that UI restricted participating in normal activities (question 9). Women who experienced UI showed a greater tendency to regard UI as a natural outcome of aging or childbirth and were less restricted by UI (experience people, 40.2\%; UI-naive subjects, 30.7\%). However, social activity was less restricted by UI problems (question 10). Social activity restriction increased along with increasing age. Additionally, more than 50\% of women thought that UI could be handled with protective products and could also be overcome by exercise or diet control (questions 11 and 12).

The expectation of handling UI with the use of protective products or exercise/diet control diminished with increasing age. Answers to questions 13-16 were expressed as a yes or no response (Table 6). More than 50\% of women aged 30 to 64 years felt discomfort because of UI (question 13), though actual activity levels were relatively less decreased (range from 21.1\% to $31.8 \%$ by aging) (question 14 ).

The percentages reflecting neglect of UI and hesitation to buy protective products for UI were not high $(25.6 \%$ and $12.0 \%)$. The number of respondents who answered "yes" to neglecting UI and hesitating to buy protective products increased along with increasing age (questions 15 and 16).

\section{DISCUSSION}

UI is a health problem that causes psychological, social, and hygienic impairment, and affects the lives of patients and their families [6].

Data from Western countries provide the most recent information on UI, with estimates of prevalence ranging from 3.9\% to $24.4 \%$ among women [7]. Reports on Japanese women over the age of 40 years (53.7\% UI prevalence) and Taiwanese women aged 65 years or older (27.7\% UI prevalence) have shown varying results $[8,9]$. Meanwhile, the prevalence of UI among Korean women has been reported to be $24.3 \%$, and it is one of the most common disabling conditions in Korea [10]. Although there are differences in UI definition, survey methods, ques- 
tionnaire structures, and study populations, our data showed a comparable incidence of $23.8 \%$ among subjects aged 30 to 64 years. Most data indicate that the prevalence of UI rises with increasing age [11,12], similar to the increase in incidence from $13.0 \%$ in women aged 30 to 39 years to $28.9 \%$ in women aged 60 to 69 years observed in our study.

As the population of older individuals increases both in number and proportion, the estimated number of adults affected by UI has increased from 49 million in 2008 to 55 million in 2013 (11.1\% increase); this number is expected to reach 60 million in 2018 (22.5\% increase worldwide) [13].

Because UI is associated with numerous comorbidities $[14,15]$ and imparts a substantial burden on affected individuals, it is important to focus on coping strategies to preserve the daily activities and emotional well-being of women affected by UI [16]. In other words, more data are needed about information sources and the effect of this information as they directly relate to people's responses and communication behaviors associated with UI.

Obviously, UI information from the mass media is common; however, in our study, subjects older than 50 years ( $50-59$ years, 51.1\%; 60-64 years, 42.2\%) and subjects who experienced UI (51.1\%) received more information from friends (question 2).

A recent review article reported that only 1 in 4 women with UI in the United States and 1 in 3 women in Europe had sought medical care for UI [17]. Altaweel and Alharbi [18] reported that less than $50 \%$ women who had incontinence discussed their symptoms with healthcare professionals. A survey conducted in 4 European countries demonstrated that only $31 \%$ of incontinent women sought professional consultation [19]. A study of UI in Japanese women showed that only $3 \%$ had ever consulted doctors or other healthcare professionals, and Chinese data show that the consultation rate was $25 \%[8,20]$. This low consultation rate may be explained by the common misconception that UI is not a disease, but a natural consequence of aging, and that UI is not curable, as evidenced by question 8 in this study. Meanwhile, among subjects with UI, 23.2\% had discussed the issue with doctors (questions 5 and 6), but a significantly higher portion of subjects (83.2\%) who had not experienced UI were willing to discuss UI with doctors. This discrepancy was derived from a greater tendency to regard UI as a natural outcome of aging or childbirth among those who had experienced UI and an inadequate expectation for UI treatment in UI-naive subjects. Additional reasons for avoiding discussion about UI were as follows (question 7): people regarded it as a minor problem (64.6\% in UI-experienced, $22.5 \%$ in UI-naive), felt ashamed (33.3\% in UI-experienced, $62.5 \%$ in UI-naive), and worried about the negative image (2.1\% in UI-experienced, $7.5 \%$ in UI-naive). Thus, we should focus on education to improve expectations about medical treatment, especially among those who have experienced UI, and provide psychological support for women to speak freely about UI as a proper coping mechanism.

UI is associated with impaired mobility, impairment of daily activity, pain/discomfort, and anxiety/depression. A cross-sectional study conducted in Turkey reported that $87.2 \%$ of women indicated that UI had a negative impact on their quality of life [2].

Although there are a variety of individual responses or attitudes to symptoms of UI, individuals perceive social pressure from others to exhibit specific behaviors. For example, incontinent women may react to social pressure by isolating themselves or having low self-esteem [18,21]. These negative aspects of the psychosocial effect of UI lead to reduced help-seeking intentions, neglect to treat UI, and hesitation to buy protective products for UI. Women may also feel social incompetence and psychosocial distress which may lead to depression, and UI has been shown to have a significant negative impact on all aspects of quality of life [22].

In our study result of questions 9 and 10, more than $50 \%$ of subjects reported a restriction of social activity because of UI. Social activity was much more restricted as the expectations of protective products or lifestyle modification diminished with age. Fortunately, actual external activity was relatively less decreased (21.1\%-31.8\%).

Korean women received most of their information on UI from the mass media, such as television or radio, but actual consultation rates were low even when UI-naive subjects were willing to discuss the issue doctors. This suggests that we should use the mass media more effectively to educate women and encourage positive healthcare-seeking behavior in Korea. Moreover, medical providers and governments should evaluate women's emotions about being incontinent and should encourage women to learn more about UI practically. Currently, most incontinent women relied on self-coping strategies, as evidenced by answers to questions 11 and 12, but using absorbent pads and adult diapers does not practically improve UI [23].

Through community services, women can learn more about the causes and treatments of UI. When misperceptions of UI are correct, more people may recognize that UI is not a natural 
result of aging or childbirth, and restriction of social activity may be prevented [24]. Additionally, healthcare providers should encourage people with UI not to be ashamed or embarrassed. Acquiring more information, using pelvic muscle floor exercise protocols with lifestyle interventions (such as prompt voiding when the sensation of the need to void occurs, decreasing caffeine intake, stopping smoking, reducing body weight, and exercising), and gaining more knowledge about how they can take action to treat UI [25].

In brief, most respondents tended to obtain information about UI through the mass media. UI-naive subjects expressed the intention to consult professionals if they developed UI, while the percentage of UI-experienced subjects who consulted professionals was very low. Thus, we should focus on education to increase medical consultations for UI.

This study has limitations because the methodological qualification using a questionnaire could be insufficient to represent UI-related issues. Data collection methods and reporting of the study materials may be inadequate. Providing the definition of UI by phone survey was demanding, as subtypes, such as urge and stress incontinence, could not defined specifically. Furthermore, we did not have subgroup analysis of UI based on the types of incontinence such as stress or urge UI.

Nevertheless, this results of this study are useful because women tend to be ashamed of UI in Korea, and this may be changed by providing efficient advertising with the right information and establishing a new perception of UI. And increasing women's understanding of UI could help people to cope with UI. In addition, patients who discuss UI with their clinicians might help the clinicians better understanding of life and social management of UI patients.

\section{REFERENCES}

1. Haylen BT, de Ridder D, Freeman RM, Swift SE, Berghmans B, Lee J, et al. An International Urogynecological Association (IUGA)/International Continence Society (ICS) joint report on the terminology for female pelvic floor dysfunction. Int Urogynecol J 2010;21:526.

2. Stewart WF, Van Rooyen JB, Cundiff GW, Abrams P, Herzog AR, Corey R, et al. Prevalence and burden of overactive bladder in the United States. World J Urol 2003;20:327-36.

3. Coyne KS, Sexton CC, Thompson CL, Milsom I, Irwin D, Kopp ZS, et al. The prevalence of lower urinary tract symptoms (LUTS) in the USA, the UK and Sweden: results from the Epidemiology of
LUTS (EpiLUTS) study. BJU Int 2009;104:352-60.

4. Kessler RC, Berglund P, Demler O, Jin R, Koretz D, Merikangas $\mathrm{KR}$, et al. The epidemiology of major depressive disorder: results from the National Comorbidity Survey Replication (NCS-R). JAMA 2003;289:3095-105.

5. Lee YS, Lee KS, Jung JH, Han DH, Oh SJ, Seo JT, et al. Prevalence of overactive bladder, urinary incontinence, and lower urinary tract symptoms: results of Korean EPIC study. World J Urol 2011;29:18590.

6. Kocak I, Okyay P, Dundar M, Erol H, Beser E. Female urinary incontinence in the west of Turkey: prevalence, risk factors and impact on quality of life. Eur Urol 2005;48:634-41.

7. Irwin DE, Milsom I, Hunskaar S, Reilly K, Kopp Z, Herschorn S, et al. Population-based survey of urinary incontinence, overactive bladder, and other lower urinary tract symptoms in five countries: results of the EPIC study. Eur Urol 2006;50:1306-14.

8. Ueda T, Tamaki M, Kageyama S, Yoshimura N, Yoshida O. Urinary incontinence among community-dwelling people aged 40 years or older in Japan: prevalence, risk factors, knowledge and self-perception. Int J Urol 2000;7:95-103.

9. Tseng IJ, Chen YT, Chen MT, Kou HY, Tseng SF. Prevalence of urinary incontinence and intention to seek treatment in the elderly. J Formos Med Assoc 2000;99:753-8.

10. Choo MS, Ku JH, Oh SJ, Lee KS, Paick JS, Seo JT, et al. Prevalence of urinary incontinence in Korean women:an epidemiologic survey. Int Urogynecol J Pelvic Floor Dysfunct 2007;18:1309-15.

11. Dooley Y, Kenton K, Cao G, Luke A, Durazo-Arvizu R, Kramer H, et al. Urinary incontinence prevalence: results from the National Health and Nutrition Examination Survey. J Urol 2008;179:656-61.

12. Nygaard IE, Lemke JH. Urinary incontinence in rural older women: prevalence, incidence and remission. J Am Geriatr Soc 1996; 44:1049-54.

13. Irwin DE, Kopp ZS, Agatep B, Milsom I, Abrams P. Worldwide prevalence estimates of lower urinary tract symptoms, overactive bladder, urinary incontinence and bladder outlet obstruction. BJU Int 2011;108:1132-8.

14. Tannenbaum C, Gray M, Hoffstetter S, Cardozo L. Comorbidities associated with bladder dysfunction. Int J Clin Pract 2013;67:10513.

15. Darkow T, Fontes CL, Williamson TE. Costs associated with the management of overactive bladder and related comorbidities. Pharmacotherapy 2005;25:511-9.

16. DuBeau CE, Levy B, Mangione CM, Resnick NM. The impact of urge urinary incontinence on quality of life: importance of patients' perspective and explanatory style. J Am Geriatr Soc 1998;46:683- 
92.

17. Zhu L, Lang J, Liu C, Han S, Huang J, Li X. The epidemiological study of women with urinary incontinence and risk factors for stress urinary incontinence in China. Menopause 2009;16:831-6.

18. Altaweel W, Alharbi M. Urinary incontinence: prevalence, risk factors, and impact on health related quality of life in Saudi women. Neurourol Urodyn 2012;31:642-5.

19. O’Donnell M, Lose G, Sykes D, Voss S, Hunskaar S. Help-seeking behaviour and associated factors among women with urinary incontinence in France, Germany, Spain and the United Kingdom. Eur Urol 2005;47:385-92.

20. Minassian VA, Drutz HP, Al-Badr A. Urinary incontinence as a worldwide problem. Int J Gynaecol Obstet 2003;82:327-38.

21. Yip SK, Cardozo L. Psychological morbidity and female urinary in- continence. Best Pract Res Clin Obstet Gynaecol 2007;21:321-9.

22. Margalith I, Gillon G, Gordon D. Urinary incontinence in women under 65: quality of life, stress related to incontinence and patterns of seeking health care. Qual Life Res 2004;13:1381-90.

23. Masue T, Wada K, Nagata C, Deguchi T, Hayashi M, Takeda N, et al. Lifestyle and health factors associated with stress urinary incontinence in Japanese women. Maturitas 2010;66:305-9.

24. Kwon CS, Lee JH. Prevalence, risk factors, quality of life, and health-care seeking behaviors of female urinary incontinence: results from the 4th Korean National Health and Nutrition Examination Survey VI (2007-2009). Int Neurourol J 2014;18:31-6.

25. Sangsawang B, Serisathien Y. Effect of pelvic floor muscle exercise programme on stress urinary incontinence among pregnant women. J Adv Nurs 2012;68:1997-2007. 